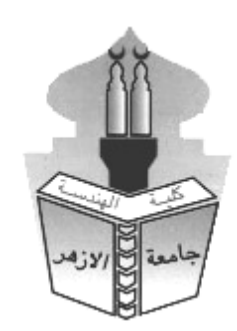

\title{
OPTIMAL DISTRIBUTED GENERATION PLACEMENT AND SIZING TO REDUCE ACTIVE POWER LOSS USING GA AND ACO ALGORITHM
}

\author{
Yousef Y. Zakaria 1 , Noha H. El-Amary 1 , R. A. Swief 2 and Amr Ibrahim ${ }^{2}$ \\ 1 Power and Machines ${ }^{1}$ Engineering Department , Faculty of Engineering, \\ Arab Academy for Science, Technology\& Maritime Transport, Cairo, gypt. \\ 2 Electrical Power and Machines ${ }^{1}$ Engineering Department, Faculty of \\ Engineering, Ain Shams University, Cairo, Egypt \\ 1-yousef.a.elec@gmail.com \\ 2-noha helamary@ hotmail.com \\ 3-rania.swief@gmail.com \\ 4-Amrmohamedhassan@yahoo.com
}

\begin{abstract}
In this paper, Genetic Algorithm (GA) and Ant colony Algorithm (ACO) optimization techniques are proposed to find optimal sizing and location for distributed generation in electrical networks. The objective function of the work relies upon a linearized model to compute the active power losses as a function of power generators. This strategy based on a strong coupling between active power and power flow taking into consideration the voltage angles. With the end goal to exhibit the adequacy of the proposed method, the proposed strategy is applied on IEEE 30-bus standard systems. Different maximum penetration level capacity of DG units with three ranges such as, $10 \%, 20 \%$ and $30 \%$ of maximum power load and various possible places of DG units among several types of DG (active, reactive or active and reactive power) are considered. Results show that the optimization tools employing GA and ACO are effective in reducing active power losses and cost loss by finding the optimal placement and sizing of DG units.
\end{abstract}

Keywords: Genetic Algorithm; Distributed Generation; Planning Of DG; Optimum Allocation Of DG; Genetic Algorithm (GA); Ant Colony Algorithm (ACO).

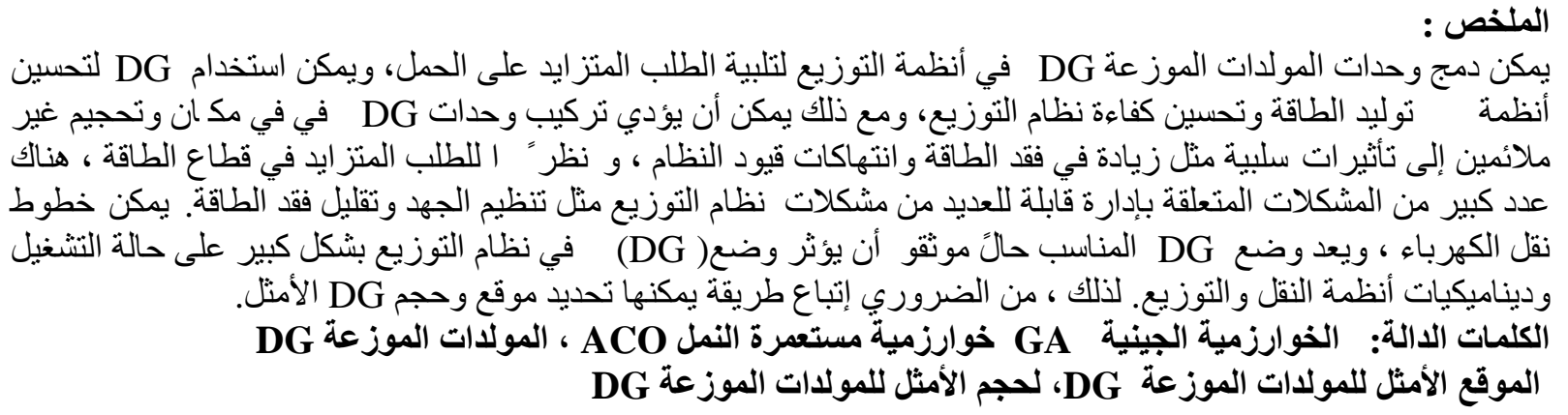




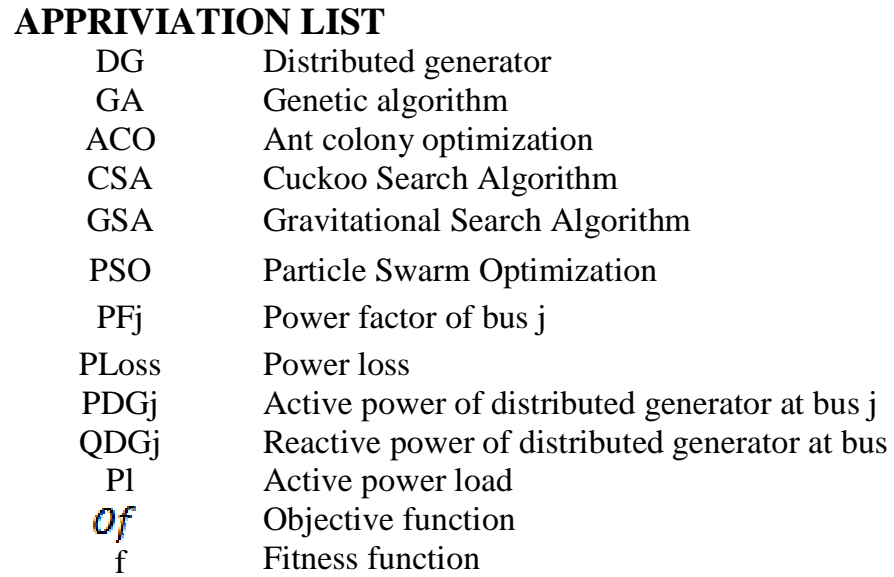

\section{INTRODUCTION}

As the electrical energy demands develop yearly, extensive amount of capital cost expected to put in new power stations, also, development of transmission and distribution lines is an important issue. These sums can be lessened by utilizing distributed generators which can be strategically placed nearer to load centers. The siting and sizing of the distributed generation (DG) are the most difficult part for most utilities to be resolved. The increasing of the penetration level of distributed generation (DG) in electrical networks will reduction the power losses, develop the voltage profile and enhance security and stability of the power system. DG offers a huge number of environmental and financial benefits, and it compatibly guarantees a reasonable limit development in distribution systems with enhanced productivity and reliability. However, these points of interest can't be completely misused if inappropriate siting and sizing of DGs are determined. The integration of DG units into distribution networks, including sizing and placements, has pulled vast interest during the most recent 15 years.

The issue of choosing the optimal conductor for a real radial distribution system in Egypt is researched utilizing an ongoing meta-heuristic Algorithm, known as salp swarm enhancement [1]. An enhancement strategy dependent on the Genetic Algorithm (GA) related to the power flow (PF) technique is utilized to enhance the distribution network (DN) performance and to distinguish the best location and size of the DG's [2]. Studying analyses and addresses the effect of the integration of customer-owned DG on the arranging of active network management (ANM) plans and maximum DG penetration limits [3]. In [4], presenting a system to obtain the optimal location and sizing of DG units to highlight these advantages considering the load variation using genetic algorithm (GA) method. Comparison of optimal DG location applying CSA, GSA, PSO and GA for minimum real power loss in radial distribution system [5]. Reference [6] proposes a data-driven technique dependent on distributionally robust optimization to determine the maximum penetration level of distributed generation (DG) for active distribution networks (ADNs). Optimal location \& Sizing of DG's using Backtracking Search Algorithm in IEEE 33-bus Distribution System [7]. In [8], proposing a novel methodology using the population depends on heuristic approach namely Particle Swarm Optimization (PSO) and New Particle Swarm Optimization (NPSO) for selecting the optimal sizing of Distributed Generator (DG) in the distribution systems. in [9], producing an optimization algorithm that employs modified flower pollination algorithm (MFPA) to select the optimal DGs allocation to minimize the system power losses, the performance of the proposed MFPA is investigated on three standard test systems; IEEE 33-bus, IEEE 69-bus and IEEE 136-bus. A real option valuation framework is proposed to choose the optimal investment strategies for DG including the investment location, size, and timing [10]. The optimal planning approach uses simulated annealing (SA) to select the optimal size and location of a mix of distributed generation (DG) candidate technologies to obtain required reliability criteria [11]. 
New hybrid method has been proposed for adding distributed generation with optimal power injections on power distribution systems to reduce power loss, this hybrid approach has been tested on IEEE 33-bus system and results are presented [12]. An efficient SPSO (Selective Particle Swarm Optimization) algorithm is presented to solve the optimal DG location problem in radial distribution systems; objective function is formulated for determining the optimal placement and sizing of distributed generation (DG) units in the distribution network for real power loss reduction and voltage profile improvement [13].

The locations of DGs are determined by using Index Vector Method (IVM) approach and Artificial Bee Colony (ABC) optimization algorithm has been employed to determine the optimum size, the proposed approach has been proved on standard 15-bus and 33-bus Radial Distribution Network (RDN) [14] the distribution system reconfiguration (DSR), for considering network configuration impact that runs in offline mode with fixed loads, and optimal DG allocation and sizing issues are studied at the same time to find an optimal condition for distribution network depends on operational thresholds and reliability improvements, Nondominated Sorting Genetic Algorithm is used to fix these problems simultaneously [15]. a Genetic Algorithm (GA) optimization method proposed to find optimal sizing and location of multi distributed generations in electrical networks, it is tested on (14, 30 and 57) IEEE standard systems [16] . Optimal distributed generation allocation using evolutionary algorithms in meshed network, the proposed method is applied on a standard IEEE 30-bus system with various DG penetration limits, the results received show the choice of the appropriate optimization algorithm and the effect of the constraints considered for optimal sizing and placement of the DGs [17]. In [18], presenting an analytical approach for optimal allocation and sizing of distributed generation (DG) in radial power Distribution networks to minimize active and reactive power losses, the proposed method is applied on 33-bus and 69-bus radial distribution test systems .in [19]. In this paper, optimization algorithms to calculate power losses has been developed to find optimal DG's sizing and siting depends on Genetic Algorithm (GA) and Ant Colony Algorithm (ACO). The genetic and ant colony algorithms offer significant advantages over many typical search of optimization technique ability to solve large-scale linear and nonlinear problems. The classification of this paper is as follows: section 2 gives brief information about GA and ACO. The formulation of methodology is given in section 3. Section 4 presents the case study on the IEEE-30 bus, test network. Finally, conclusions are summarized in section 5 .

\section{THE PROBOSED ALGORITHMS}

\section{A. GENETIC ALGORITHM}

Optimization tools have great importance for optimal sizing and allocation of DG. GA is the most optimization tool used for solving this problem. GA is dependent on the natural selection and genetics [21]. It is a search based optimization algorithm and proper for solving the unconstrained optimization problems. To start the search steps, generate the initial population. The size of population should be determined and fixed pending the GA. In the second phase, the fitness function is estimated for given populations. Then, a new population it must be produced to find the optimal solution. There are three operators to estimated population of design vectors [21]; Propagation: This operator is used to determine the strings with the above-average fitness value from population and insert their multiple copies based on the probabilistic procedure.

Crossover: it should be implemented after the propagation. Its goal is to create new strings in the population by exchanging the information. Generally, two strings are selected randomly from the population and some portions of those are exchanged between selected strings. Mutation: After the crossover operation, the mutation operator must be applied to the new strings. The specific bits of the strings 0 to 1 or vice versa changed by this operator. Each generation consists of 
propagation, crossover and mutation. Fig. 1 shows the flowchart of the proposed GA-based solution technique.

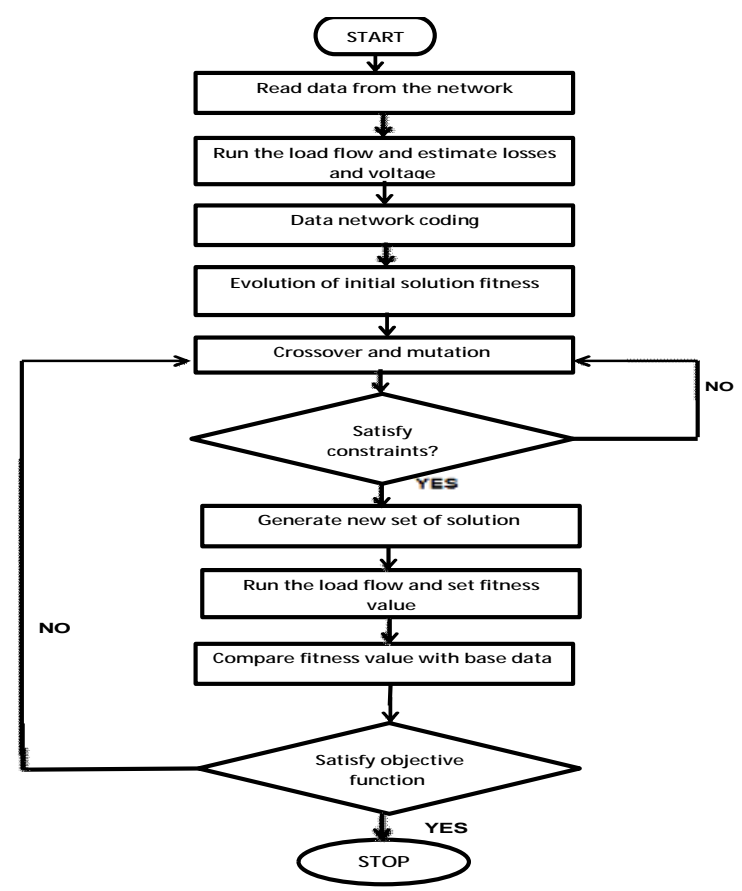

Fig.(1): GA technique flow chart

\section{B. ANT COLONY ALGORITHM}

\section{General Aspects}

The general ACO algorithm derived from the behavior of real ants is illustrated in Fig. 2. The procedure of the ACO algorithm manages the scheduling of three activities .The first step consists mainly in the initialization of the pheromone trail. In the iteration (second) step, each Ant constructs a complete solution to the problem according to a probabilistic state transition rule. The state transition rule depends mainly on the state of the pheromone. The third step updates quantity of pheromone; a pheromone updating rule is applied in two phases. First is an evaporation phase where a fraction of the pheromone evaporates, and then there is a reinforcement phase increasing amount of pheromone on path with high quality solutions. This process is iterated until a stopping criterion is reached.[20]

\begin{tabular}{|l|}
\hline Step 1. Initialization \\
- Initialize pheromone trail \\
Step 2. Solution construction \\
- For each ant Repeat \\
Solution construction using the pheromone trail \\
Step 3. Update the pheromone trail \\
Until stopping criteria
\end{tabular}

Fig. 2. A generic ACO algorithm. 
Several different ways have been proposed to translate the above principles into a computational procedure to solve the optimization problem. The optimization approach proposed for in this paper is based on the ACO algorithm presented in [20], and outlined in the next subsection.

\section{Applying ACO to DG Placement and sizing Problem}

Applying ACO to DG Placement Problem Main steps of proposed ACO algorithm are listed below: Step1) Graph representation of search space First of all, we seek to devise a representation structure that is suitable for ants to search for solutions to the problem. The searching space of the problem is shown in Fig. 3.

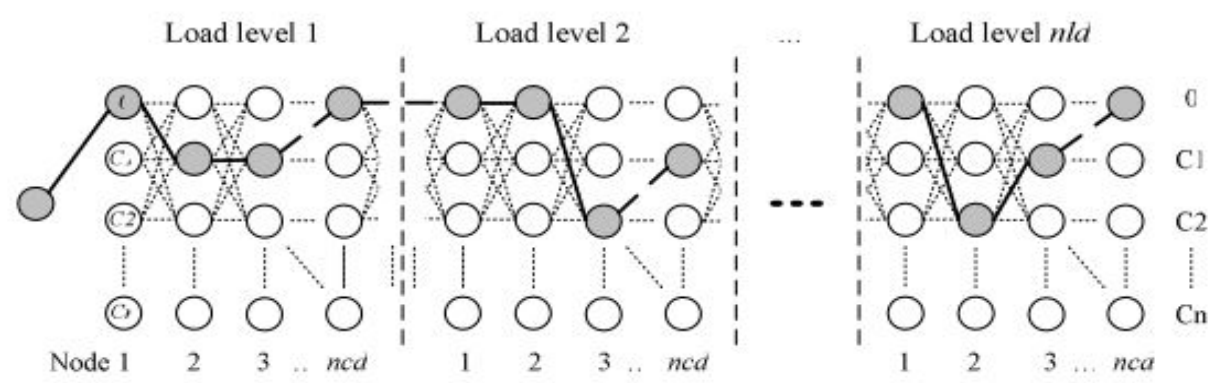

Fig. (3): Searching space of the problem.

All possible candidate capacity values in site $\mathrm{n}$ are represented by the states in the searching space in correspondence to stage $n$. The number of stages for each load level is equal to the number of candidate nodes of distribution system for DG placement. So, total number of stages is equal to (nld $\times \mathrm{ncd}$ ). A solution to the problem is produced after an ant completes its decision process for the sub-paths forming a tour.

Step2): ACO initialization in the beginning of ACO algorithm, the pheromone values of edges in search space are all initialized to a constant value $\tau 0>0$. This initialization causes ants choose their paths randomly and therefore, search the solution space more effectively.

Step3): Ant dispatch in this step, the ants are dispatched and solutions are constructed based on the level of pheromone on edges. Each ant will start its tour at the home colony and choose one of the states in the next stage to move according to following transition probability.

$$
P_{i j}(t)=\frac{\left[\tau_{i j}(t)\right]}{\sum_{h \in \Delta_{i}}\left[\tau_{i j}(t)\right]}
$$

Where, $\tau \mathrm{ij}(\mathrm{t})$ is the total pheromone deposited on edge $\mathrm{ij}$ at iteration $\mathrm{t}$, and $\Delta \mathrm{i}$ represents the set of available edges which ant can choose at state i. After each ant ends its tour, a new solution for DG placement is generated which must be evaluated using fitness function.

Step4): Fitness function in this step, the fitness of tours generated by ants is assessed based on fitness function. The fitness function of the problem is defined as a penalty factor to the infeasible solutions (i.e., the ones violating the constraints). To speed up the convergence properties of algorithm and at the same time, to use the information that may still be useful in rejected tours, this penalty factor is linearly increased (through iterations) from zero toward a very high value. Step5): Pheromone update the aim of the pheromone value update rule is to increase the pheromone values on solution components that have been found in high fitness solutions. Also, from a practical point of view, pheromone evaporation is needed to avoid a too rapid 
convergence of the algorithm toward a sub-optimal region. It implements a useful form of forgetting, favoring the exploration of new areas in the search space. We use the following update rule in our study:

$$
\tau_{i j}(t+1)=\left\{\begin{array}{c}
\max \left\{(1-\rho) \tau_{i j}(t)+Q \cdot F\left(\Omega_{B}(t)\right), \tau_{\min }(t)\right\}, \\
\text { if }(i, j) \in \Omega_{\theta}(t), \\
\max \left\{(1-\rho) \tau_{i j}(t), \tau_{\min }(t)\right\} \\
\text { otherwise, }
\end{array}\right.
$$

Where, $0<\rho<1$ is pheromone evaporation rate. $\Omega \mathrm{B}(\mathrm{t})$ is the best tour found until the end of iteration $\mathrm{t}$, which is stored in a specific list variable and replaced each time some ant finds a tour with better quality function value. $F(\Omega B(t))$ is the quality function value corresponding to $\Omega B(t)$. Q is a heuristic variable which control amount of pheromone addition on the best tour. $\tau \min (\mathrm{t})$ is lower bound of pheromone which results in a small probability for an ant to choose a certain edge; still the probability will be greater than zero. This lower bound is a function of the iteration counter as bellow:

$$
\tau_{\min }(t)=\tau_{\min }\left(1-\frac{t}{t_{\max }}\right)
$$

Where, $\tau$ min is initial lower bound of pheromone.

Step6) Convergence determination the steps 3-5 continue until the iteration counter reaches the predefined maximum number which determines experimentally. The best tour selected among all iterations implies the optimal DG placement solution. Fig. 4 shows the flowchart of the proposed ACO-based solution technique [20].

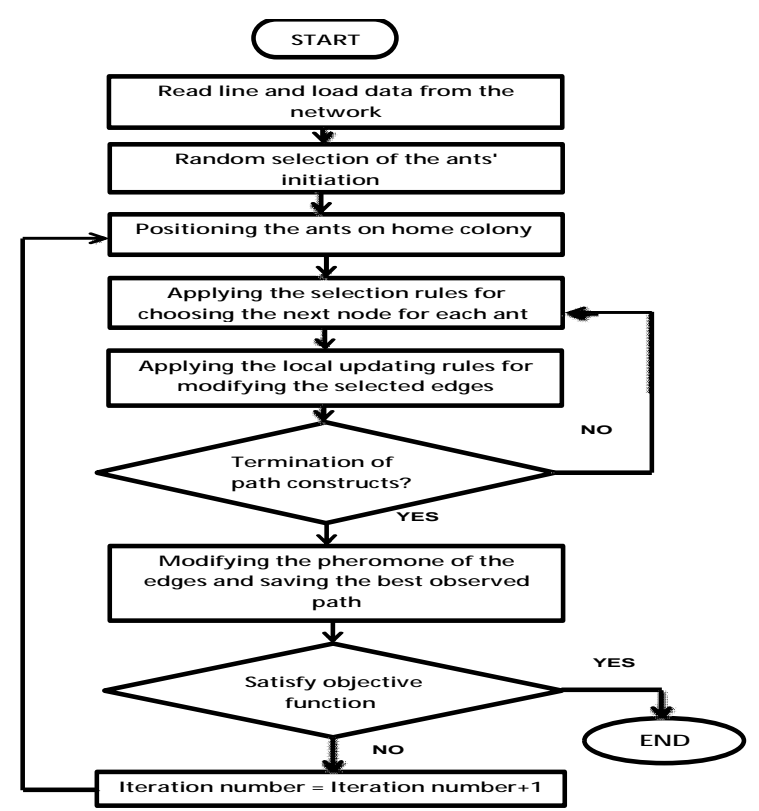

Fig. (4): Flowchart of the proposed ACO-based solution algorithm

\section{PROBLEM FORMULATION}

The main aim of this paper is to study the reliable performance of the system after placing the DG optimally at a suitable site. Since the purpose of DG is to decrease the total active power loss and improving the voltage profile, the installation of DG units at non-optimal places may not give accurate results which will be useful for improving the 
system performance. However the losses cannot be totally removed, but they can be pushed down to an acceptable value. Since the impact of distributed generation on system performance based on system operating conditions and the type of the distributed generation, it is important to use some solutions in planning and operation to reach solutions for the best performance. The first objective is to decrease the total real power loss in the power system accounting DG which expressed as follows [5]:

Minimization of

$\mathrm{f}=\sum_{i=1}^{N} P_{\text {Loss }_{i}}$

$P_{\text {Loss }_{i}}=\left|\mathrm{I}_{i}\right|^{2} R_{i}$

(2)

Where $I_{i}$ is the current of branch $i$, and $R_{i}$ is the resistance of branch $i$

With DG Subject to real power constraints given by:

$\sum_{j=1}^{N} P_{D G j}=\sum_{j=1}^{N} P_{D j}+\sum_{i=1}^{N} P_{\text {Loss }}$

The inequality constraints on $P_{D G j}$ of $D G$ given by:

$P_{D G_{j}}^{\operatorname{mini}} \leq P_{D G_{j}} \leq P_{D G_{j}}^{\max }$

The inequality constraints on $Q_{D G i}$ of $D G$ given by:

$Q_{\nu l_{j}}^{\operatorname{mini}} \leq Q_{D G j} \leq Q_{\nu G_{j}}^{\max }$

The equality constraints on $P_{D G j}$ and $Q_{D G j}$ of $D G$ with constant power factor given by:

$P . F_{\cdot j}=\cos \theta_{j}$

$\tan ^{-1} \theta_{j}=\frac{Q_{L j}}{P_{L j}}$

The $Q_{D G i}$ given by:

$Q_{D G j}=\tan ^{-1} \theta_{j} \times P_{D G j}$

where $\mathrm{f}$ is the total loss of the system, $P_{\text {loss }}$ is the real power loss at branch i, $P_{C j}$ is the active power generation at bus $\mathrm{J}, \mathrm{PG}$ is the active power generated, $P_{D j}$ is the total power demand, $P_{D C j}$ is the real power generation for distributed generators, $Q_{D G j}$ is the reactive power generation for distributed generator, $P_{D G \text { imin }}$ and $P_{D G \text { jmax }}$ are the minimum and maximum active power generation limits at bus i for DG values, $Q_{D \text { Fjmin }}$ and $Q_{D G j \max }$ are the minimum and maximum reactive power generation limits at bus i for DG values, $P . F_{j}$ is the power factor of bus $\mathrm{i}, P_{L j}$ is the active power load at bus $\mathrm{i}, Q_{L i}$ is the reactive 
power load at bus j $\theta_{j}$ the angle between $P_{L}$ and $Q_{L}$ at bus $\mathrm{j}$, and $\mathrm{N}$ is the total number of buses in the system. The second objective is directed towards the improvement in voltage profile of the bus system represented by the objective function (Of) governed by the relation (9):

of $-1-\sum_{i=1}^{N} v(j)$

Here of $=$ Objective Function in terms of voltages of all the buses and $v(\mathrm{j})$ is the voltage at bus $i$ in the system. The GA and ACO algorithms are used for the optimal sizing of the DG's taking the minimum system losses as the constraint. The optimization algorithm runs until there is no more reduction in system losses taking in to account that the constraints are obeyed, the power loss reduction and cost loss reduction expressed as the followings equations:

$$
\begin{aligned}
& P_{\text {LOSS }}=\frac{\sum_{R}\left(P_{\text {LOSS }}\right)_{\text {nODC }}-\Gamma_{\left(P_{\text {LOSE }}\right)_{\text {witi } D C}}}{\sum\left(P_{\text {LOSS }}\right)_{\text {nODG }}} \times 100 \\
& C_{\text {Loss }}=T \times \sum P_{\text {Los }} \\
& C_{\text {LOSS }}=\frac{\Sigma\left(C_{\text {LOSS }}\right)_{\text {nODG }}-\Sigma\left(C_{\text {LOSS }}\right)_{\text {with DG }}}{\sum\left(C_{\text {LOSS }}\right)_{\text {nODG }}} \times 100 \\
& P_{\text {LOSs }_{R}} \text { i active power loss reduction } \\
& \left(P_{\text {Luss }}\right)_{n D D} \text { : the power lass with out adding distributed generators } \\
& \left(P_{\text {Loss }}\right)_{\text {with } D G} \text { : the pover loss with adding distributed generators } \\
& C_{\text {Lass }} \text { : the cost of total power loss } \\
& T \text { : the tarif per } 1 \mathrm{MW}
\end{aligned}
$$

\section{IV.CASE STUDY AND RESULTS}

The proposed optimization technique has been simulated in MATLAB environment and tested for distribution systems. To verify the effectiveness and efficiency of the GA and ACO techniques, they have been applied to IEEE 30-bus system, which has its schematic diagram and all data shown in fig.5, table 1 , table 2 and table 3 . In this paper, minimization of the active power loss, cost of active power loss -and enhancement in the voltage profile are considered as objective functions. The proposed method is applied to an IEEE 30-bus system with the total active load of 283.4 MW and reactive load of 126.2 MVAR. The real power loss is 18.744 MW when calculated using load flow for the base case, bus one selected as slack bus, from economical case we assume $1000 \mathrm{LE}$ is the tariff per $1 \mathrm{MW}$ power loss. 
OPTIMAL DISTRIBUTED GENERATION PLACEMENT AND SIZING TO REDUCE ACTIVE POWER LOSS USING GA AND ACO ALGORITHM

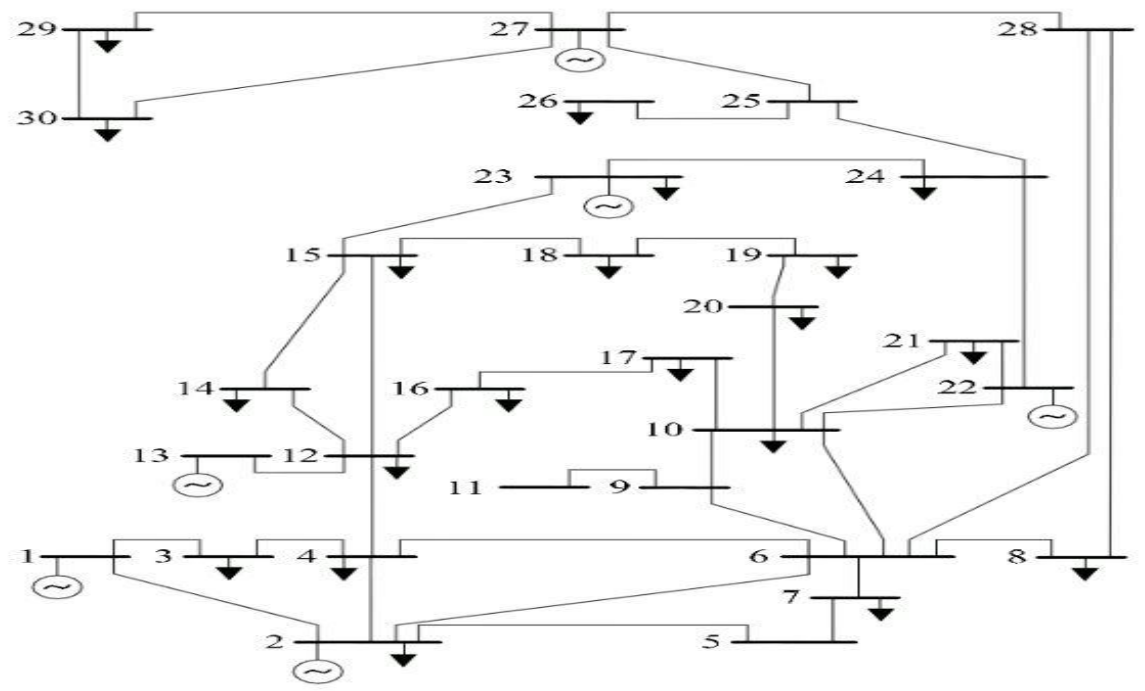

Fig. (5): schematic diagram of IEEE 30- bus system

Table (1): line data of IEEE 30-bus system

\begin{tabular}{|c|c|c|c|c|c|c|c|}
\hline \multirow{2}{*}{$\begin{array}{c}\text { Line } \\
\text { number }\end{array}$} & \multirow{2}{*}{$\begin{array}{c}\text { From } \\
\text { Bus }\end{array}$} & \multirow{2}{*}{$\begin{array}{c}\text { To } \\
\text { Bus }\end{array}$} & \multicolumn{2}{|c|}{ Line impedance (p.u.) } & \multirow{2}{*}{$\begin{array}{l}\text { Half line charging } \\
\text { susceptance (p.u.) }\end{array}$} & \multirow{2}{*}{$\begin{array}{l}\text { MVA } \\
\text { Rating }\end{array}$} & \multirow{2}{*}{$\begin{array}{c}\text { Transformer } \\
\text { Tap setting } \\
\text { value (p.u.) } \\
\end{array}$} \\
\hline & & & Resistance & Reactance & & & \\
\hline $\mathbf{1}$ & 1 & 2 & 0.2 & 0.06 & 0.02 & 130 & \\
\hline 2 & $\mathbf{1}$ & 3 & 0.05 & 0.2 & 0.02 & 130 & $\mathbf{1}$ \\
\hline 3 & 2 & 4 & 0.06 & 0.2 & 0.02 & 65 & $\mathbf{1}$ \\
\hline 4 & 2 & 5 & 0.05 & 0.2 & 0.021 & 130 & $\overline{1}$ \\
\hline 5 & $\overline{2}$ & 6 & 0.06 & 0.2 & 0.02 & 65 & $\mathbf{1}$ \\
\hline 6 & 3 & 4 & 0.0132 & 0.04 & 0.0042 & 130 & $\mathbf{1}$ \\
\hline 7 & 4 & 6 & 0.012 & 0.0414 & 0.005 & 90 & $\mathbf{1}$ \\
\hline 8 & 4 & 12 & $\mathbf{0}$ & 0.3 & $\mathbf{0}$ & 65 & 0.932 \\
\hline 9 & 5 & 7 & 0.05 & 0.12 & 0.01 & 70 & 1 \\
\hline 10 & 6 & 7 & 0.03 & 0.082 & 0.009 & 130 & $\overline{\mathbf{1}}$ \\
\hline 11 & 6 & 8 & 0.012 & 0.042 & 0.0045 & 32 & $\mathbf{1}$ \\
\hline 12 & 6 & 9 & 0 & 0.208 & 0 & 65 & 0.978 \\
\hline 13 & 6 & 10 & o & 0.556 & $\mathbf{0}$ & 32 & 0.969 \\
\hline 14 & 6 & 28 & 0.0169 & 0.0599 & 0.065 & 32 & 1 \\
\hline 15 & 8 & 28 & 0.0636 & 0.2 & 0.0214 & 32 & 1 \\
\hline 16 & 9 & 11 & 0 & 0.208 & 0 & 65 & $\overline{1}$ \\
\hline 17 & 9 & 10 & 0 & 0.11 & 0 & 65 & I \\
\hline 18 & 10 & 20 & 0.0936 & 0.209 & o & 32 & 1 \\
\hline 19 & 10 & 17 & 0.0324 & 0.0845 & 0 & 32 & 1 \\
\hline 20 & 10 & 21 & 0.0348 & 0.0749 & 0 & 32 & 1 \\
\hline 21 & 10 & 22 & 0.0727 & 0.1499 & 0 & 32 & 1 \\
\hline 22 & 12 & 13 & o & 0.14 & o & 65 & 1 \\
\hline 23 & 12 & 14 & 0.1231 & 0.2559 & 0 & 65 & 1 \\
\hline 24 & 12 & 15 & 0.0662 & 0.1304 & 0 & 32 & $\overline{1}$ \\
\hline 25 & 12 & 16 & 0.0945 & 0.1997 & 0 & 32 & 1 \\
\hline 26 & 14 & 15 & 0.221 & 0.1997 & 0 & 16 & 1 \\
\hline 27 & 15 & 18 & 0.1073 & 0.2185 & 0 & 16 & 1 \\
\hline 28 & 15 & 23 & 0.1 & 0.202 & 0 & 16 & 1 \\
\hline 29 & 16 & 17 & 0.0824 & 0.1923 & 0 & 16 & 1 \\
\hline 30 & 18 & 19 & 0.0639 & 0.1292 & 0 & 16 & 1 \\
\hline 31 & 19 & 20 & 0.034 & 0.068 & o & 32 & 1 \\
\hline 32 & 21 & 23 & 0.0116 & 0.0236 & 0 & 32 & 1 \\
\hline 33 & 22 & 24 & 0.115 & 0.179 & 0 & 16 & I \\
\hline 34 & 23 & 24 & 0.132 & 0.27 & 0 & 16 & 1 \\
\hline 35 & 24 & 25 & 0.1885 & 0.3292 & 0 & 16 & 1 \\
\hline 36 & 25 & 26 & 0.2544 & 0.38 & 0 & 16 & $\overline{1}$ \\
\hline 37 & 25 & 27 & 0.1093 & 0.2087 & o & 16 & 1 \\
\hline 38 & 27 & 29 & 0.2198 & 0.4153 & 0 & 16 & 1 \\
\hline 39 & 27 & 30 & 0.24 & 0.58 & 0 & 16 & 1 \\
\hline 40 & 28 & 27 & 0 & 0.396 & 0 & 65 & 0.968 \\
\hline 41 & 29 & 30 & 0.13 & 0.4 & 0 & 16 & 1 \\
\hline
\end{tabular}


Table (2): bus voltage and load and generation of IEEE 30-bus system

\begin{tabular}{|c|c|c|c|c|c|c|}
\hline \multirow[b]{2}{*}{$\begin{array}{l}\text { Bus } \\
\text { Number }\end{array}$} & \multicolumn{2}{|c|}{ Bus Voltage } & \multicolumn{2}{|c|}{ Generation } & \multicolumn{2}{|c|}{ Load } \\
\hline & $\begin{array}{l}\text { Magnitude } \\
\text { (p.u) }\end{array}$ & $\begin{array}{c}\text { Phase } \\
\text { Angle } \\
\text { (Degree) }\end{array}$ & $\underset{(\mathbf{P W})}{\mathbf{P}}$ & $\underset{\mathbf{M V A R}}{\mathbf{Q}}$ & $\underset{(\mathbf{M W})}{\mathbf{P}}$ & $\underset{\text { MVAR) }}{\mathbf{Q}}$ \\
\hline $\mathbf{1}$ & 1.06 & O & $\mathbf{0}$ & $\mathbf{0}$ & $\mathbf{0}$ & $\mathbf{0}$ \\
\hline 2 & $\mathbf{1}$ & $\mathbf{0}$ & 40 & 50 & 21.7 & 12.7 \\
\hline 3 & $\mathbf{1}$ & $\mathbf{0}$ & $\mathbf{0}$ & $\mathbf{0}$ & 2.4 & 1.2 \\
\hline 4 & $\mathbf{1}$ & $\mathbf{0}$ & $\mathbf{0}$ & $\mathbf{0}$ & 7.6 & 1.6 \\
\hline 5 & $\mathbf{1}$ & $\mathbf{0}$ & $\mathbf{0}$ & 37 & 94.2 & 19 \\
\hline 6 & $\mathbf{1}$ & $\mathbf{0}$ & $\mathbf{0}$ & $\mathbf{0}$ & $\mathbf{0}$ & $\mathbf{0}$ \\
\hline 7 & $\mathbf{I}$ & $\mathbf{0}$ & $\mathbf{0}$ & $\mathbf{0}$ & 22.8 & 10.9 \\
\hline 8 & $\mathbf{1}$ & $\mathbf{0}$ & $\mathbf{0}$ & $\mathbf{3 7 . 3}$ & 30 & 30 \\
\hline 9 & $\mathbf{1}$ & $\mathbf{0}$ & $\mathbf{0}$ & O & $\mathbf{0}$ & $\mathbf{0}$ \\
\hline 10 & $\mathbf{1}$ & $\mathbf{0}$ & $\mathbf{0}$ & 19 & 5.8 & 2 \\
\hline 11 & $\overline{1}$ & $\mathbf{0}$ & $\mathbf{0}$ & 16.2 & $\mathbf{0}$ & o \\
\hline 12 & $\mathbf{1}$ & $\mathbf{0}$ & $\mathbf{0}$ & $\mathbf{0}$ & 11.2 & 7.5 \\
\hline 13 & $\mathbf{1}$ & $\mathbf{0}$ & $\mathbf{0}$ & 10.6 & $\mathbf{0}$ & $\mathbf{0}$ \\
\hline 14 & $\overline{1}$ & $\mathbf{0}$ & $\mathbf{0}$ & o & 6.2 & 1.6 \\
\hline 15 & $\mathbf{1}$ & $\mathbf{0}$ & $\mathbf{0}$ & $\mathbf{0}$ & 8.2 & 2.5 \\
\hline 16 & $\mathbf{1}$ & $\mathbf{0}$ & $\mathbf{0}$ & $\mathbf{0}$ & 3.9 & 1.8 \\
\hline 17 & $\overline{1}$ & $\mathbf{0}$ & $\mathbf{0}$ & $\mathbf{0}$ & 9 & 5.8 \\
\hline 18 & $\mathbf{1}$ & $\mathbf{0}$ & $\mathbf{0}$ & $\mathbf{0}$ & 3.2 & 0.9 \\
\hline 19 & $\mathbf{I}$ & $\mathbf{0}$ & $\mathbf{0}$ & $\mathbf{0}$ & 9.5 & 3.4 \\
\hline 20 & $\mathbf{1}$ & $\mathbf{0}$ & $\mathbf{0}$ & $\mathbf{0}$ & 2.2 & 0.7 \\
\hline 21 & $\mathbf{1}$ & $\mathbf{0}$ & $\mathbf{0}$ & $\mathbf{0}$ & 17.5 & 11.2 \\
\hline 22 & $\mathbf{1}$ & $\mathbf{0}$ & $\mathbf{0}$ & $\mathbf{0}$ & $\mathbf{O}$ & $\mathbf{0}$ \\
\hline 23 & $\mathbf{1}$ & $\mathbf{0}$ & $\mathbf{0}$ & $\mathbf{0}$ & 3.2 & 1.6 \\
\hline 24 & $\overline{1}$ & 0 & 0 & 4.3 & 8.7 & 6.7 \\
\hline 25 & $\mathbf{1}$ & O & O & 0 & O & O \\
\hline 26 & 1 & о & O & O & 3.5 & 2.3 \\
\hline 27 & I & O & 0 & 0 & $\mathbf{0}$ & O \\
\hline 28 & $\mathbf{1}$ & O & $\mathbf{0}$ & O & $\mathbf{0}$ & $\mathbf{0}$ \\
\hline 29 & 1 & $\mathbf{0}$ & $\mathbf{0}$ & O & 2.4 & 0.9 \\
\hline 30 & 1 & O & O & $\mathbf{0}$ & 10.6 & 1.9 \\
\hline
\end{tabular}

Table (3): generators data of IEEE 30-bus system

\begin{tabular}{|c|c|c|c|}
\hline $\begin{array}{c}\text { Generator } \\
\text { Number }\end{array}$ & $\begin{array}{c}\text { BUS } \\
\text { Number }\end{array}$ & (M W) & (M W) \\
\hline G1 & $\mathbf{1}$ & $\mathbf{0}$ & $\mathbf{8 0}$ \\
\hline G2 & 2 & 0 & 80 \\
\hline G3 & 13 & 0 & 50 \\
\hline G4 & 22 & 0 & 55 \\
\hline G5 & 23 & 0 & 30 \\
\hline G6 & 27 & 0 & 40 \\
\hline
\end{tabular}

\section{Case 1: 10\% Penetration Level}

The proposed methods are applied to IEEE 30-bus system with $10 \%$ of load penetration level, $10 \%$ of active power and reactive power load are $28.34 \mathrm{MW}$ and 12.62 MVAR. Table 4 represents the comparison of active power loss, cost of active power loss and the percentage of power and cost loss reduction without DGs and with adding active power DGs, reactive power DGs and active reactive power DGs with constant power factor of bus with respect to its load, using GA and ACO. Fig.4 represents the comparison of average voltage profile of IEEE 30-bus without DGs and with implementing active power DGs, reactive power DGs and active reactive power DGs with constant power factor of bus with respect to its load using GA and ACO. For this case, two active power DG units are optimally sized and placed using ACO technique; the size and location of each DG are given in Table I. show that in fig. 6 and table 5 the bus voltage profile, three active and reactive power DG units are optimally sized and placed using GA technique, the size and location of each DG and cost of power loss are given in table 4. 
OPTIMAL DISTRIBUTED GENERATION PLACEMENT AND SIZING TO REDUCE ACTIVE POWER LOSS USING GA AND ACO ALGORITHM

Table (4): DG placement and sizing and cost of power loss by GA and ACO for IEEE 30-bus system (case1)

\begin{tabular}{|c|c|c|c|c|c|c|c|c|c|c|c|}
\hline $\begin{array}{c}\text { DG } \\
\text { NUM BER }\end{array}$ & Techniques & $\begin{array}{l}\text { DG } \\
\text { Types }\end{array}$ & \multicolumn{4}{|c|}{ Implemented DG Schedule } & \multirow[t]{2}{*}{$\begin{array}{c}\text { DGs } \\
\text { (MW) }\end{array}$} & \multirow[t]{2}{*}{$\begin{array}{c}\text { DGS } \\
\text { (MVAR) }\end{array}$} & \multirow{2}{*}{\begin{tabular}{|c|}
$\begin{array}{c}\text { Ploss } \\
\text { (M W) }\end{array}$ \\
18.744 \\
\end{tabular}} & \multirow{2}{*}{$\begin{array}{c}\begin{array}{c}\text { Cost Loss } \\
\text { (LE) }\end{array} \\
18744\end{array}$} & \multirow{2}{*}{$\begin{array}{c}\begin{array}{c}\text { Cost\&P } \\
\text { Loss } \\
\text { Reduction } \\
(\%)\end{array} \\
\mathbf{0}\end{array}$} \\
\hline NO DG & & & & & & & & & & & \\
\hline \multirow{14}{*}{ 2DG } & \multirow{7}{*}{ GA } & \multirow[b]{2}{*}{$\mathbf{P}$} & BUS & 5 & 15 & & \multirow[b]{2}{*}{28.342} & \multirow[b]{2}{*}{0.0} & \multirow[b]{2}{*}{14.661} & \multirow[b]{2}{*}{14661} & \multirow[b]{2}{*}{21.8} \\
\hline & & & $\begin{array}{c}\text { Size } \\
(\mathrm{M} \mathrm{W})\end{array}$ & 28.34 & 0.002 & & & & & & \\
\hline & & \multirow{2}{*}{$\mathbf{Q}$} & BUS & 4 & 2 & & \multirow{2}{*}{0.0} & \multirow{2}{*}{12.7} & \multirow{2}{*}{18.269} & \multirow{2}{*}{18269} & \multirow{2}{*}{2.534} \\
\hline & & & $\begin{array}{c}\text { Size } \\
\text { (MVAR) }\end{array}$ & 3.1 & 9.6 & & & & & & \\
\hline & & \multirow{3}{*}{$\begin{array}{l}\mathbf{P} \\
\boldsymbol{Q} \\
\mathbf{Q}\end{array}$} & BUS & 24 & 17 & & \multirow{3}{*}{28.34} & \multirow{3}{*}{20.243} & \multirow{3}{*}{14.55} & \multirow{3}{*}{14550} & \multirow{3}{*}{22.4} \\
\hline & & & $\begin{array}{l}\text { Size } \\
(M \text { w) }\end{array}$ & 15.72 & 12.62 & & & & & & \\
\hline & & & $\begin{array}{c}\text { Size } \\
\text { (MVAR) }\end{array}$ & 12.11 & 8.133 & & & & & & \\
\hline & & & BUS & 5 & 30 & & \multirow{2}{*}{28.34} & \multirow{2}{*}{0.0} & & & \\
\hline & & $\boldsymbol{P}$ & $\begin{array}{l}\text { Size } \\
(M \mathrm{w})\end{array}$ & 20 & 8.34 & & & & 14.531 & 14531 & 22.5 \\
\hline & & & BUS & 21 & 26 & & & & & & \\
\hline & ACO & $\mathbf{Q}$ & $\begin{array}{c}\text { Size } \\
\text { (MVAR) }\end{array}$ & 10 & 2.62 & & 0.0 & 12.62 & 18.448 & 18448 & 1.6 \\
\hline & & $\mathbf{D}$ & BUS & 21 & 24 & & & & & & \\
\hline & & $\boldsymbol{\varepsilon}$ & $\begin{array}{c}\text { Size } \\
(M W)\end{array}$ & 14.2 & 14.2 & & 28.4 & 20.04 & 14.412 & 14412 & 2311 \\
\hline & & $\mathbf{Q}$ & $\begin{array}{c}\text { Size } \\
\text { (MVAR) }\end{array}$ & 9.1 & 10.94 & & & & & & \\
\hline & & & BUS & 5 & 5 & 7 & & & & & \\
\hline & & $\mathbf{P}$ & $\begin{array}{l}\text { Size } \\
(M W)\end{array}$ & 19.8 & 2.13 & 6.44 & 28.4 & 0.0 & 14.646 & 14646 & 21.9 \\
\hline & & & BUS & 2 & 26 & 12 & & & & & \\
\hline & GA & $\mathbf{Q}$ & $\begin{array}{c}\text { Size } \\
\text { (MVAR) }\end{array}$ & 10.1 & 2.4 & 0.2 & 0.0 & 12.7 & 18.254 & 18254 & 2.61 \\
\hline & & & BUS & 5 & 19 & 19 & & & & & \\
\hline & & $\boldsymbol{\varepsilon}$ & $\begin{array}{l}\text { Size } \\
(M \text { W })\end{array}$ & 21.55 & 2.912 & 3.9 & 28.4 & 6.8 & 14.582 & 14582 & 22.2 \\
\hline & & $\mathbf{Q}$ & $\begin{array}{c}\text { Size } \\
\text { (MVAR) }\end{array}$ & 4.35 & 1.04 & 1.4 & & & & & \\
\hline 3DG & & & BUS & 5 & 30 & 30 & & & & & \\
\hline & & $\mathbf{P}$ & $\begin{array}{l}\text { Size } \\
(M W)\end{array}$ & 20 & 4.2 & 4.2 & 28.4 & 0.0 & 14.524 & 14524 & 22.514 \\
\hline & & & BUS & 23 & 26 & 30 & & & & & \\
\hline & ACO & $\mathbf{Q}$ & $\begin{array}{c}\text { Size } \\
\text { (MVAR) }\end{array}$ & 10 & 1.31 & 1.31 & 0.0 & 12.62 & 18.448 & 18448 & 1.6 \\
\hline & & & BUS & 24 & 21 & 30 & & & & & \\
\hline & & $\boldsymbol{\alpha}$ & $\begin{array}{c}\text { Size } \\
(\mathrm{M} \text { W) }\end{array}$ & 9.45 & 9.45 & 9.45 & 28.4 & 15.1 & 14.607 & 14607 & 22.1 \\
\hline & & $\mathbf{Q}$ & $\begin{array}{c}\text { Size } \\
\text { (MVAR) }\end{array}$ & 7.3 & 6.05 & 1.7 & & & & & \\
\hline
\end{tabular}


Table 5: bus voltage profile (case 1)

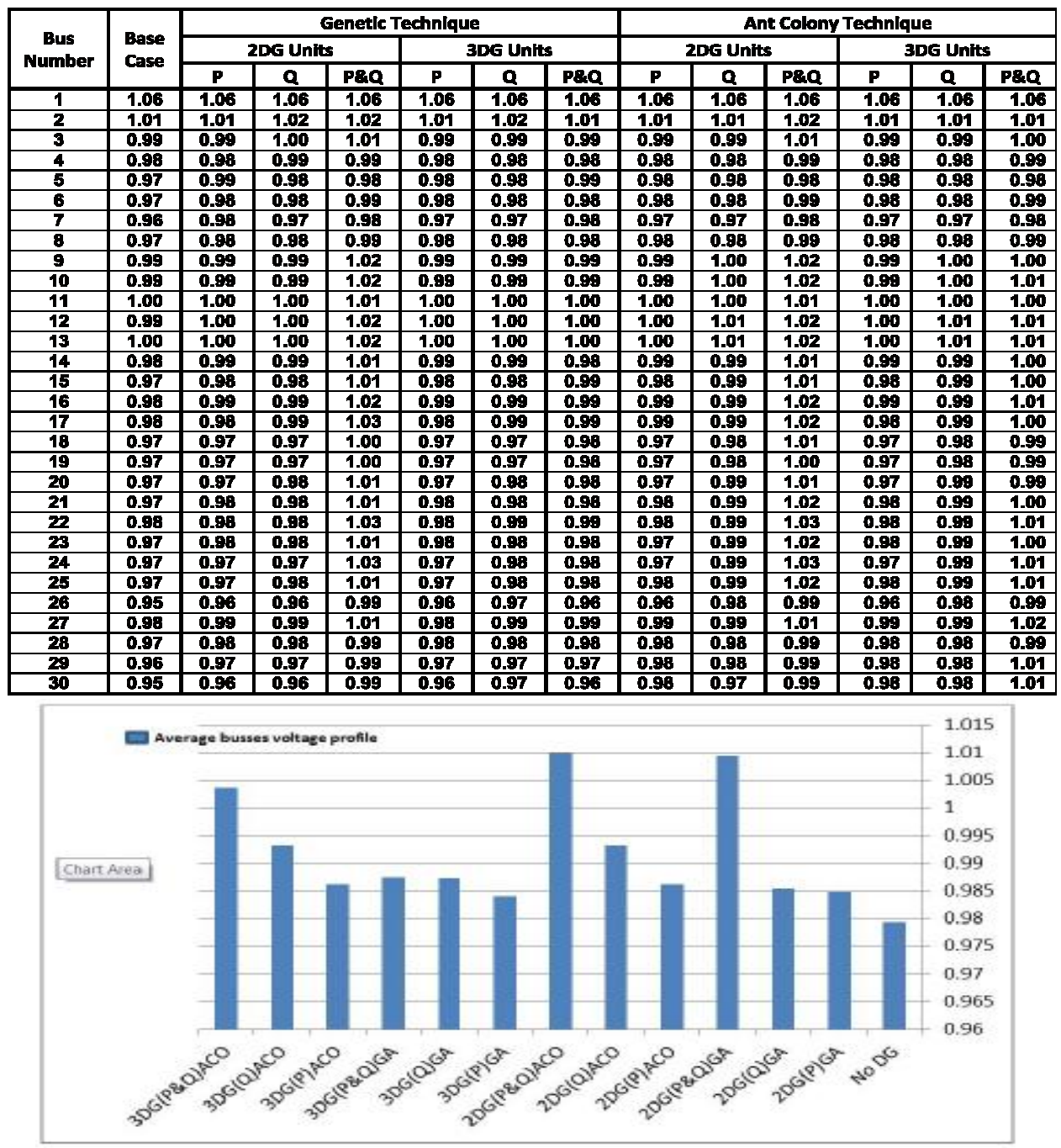

Fig. (5): Average voltages profile of IEEE 30- bus system (case1)

Case 2: $20 \%$ Penetration Level

The proposed methods are applied to IEEE 30-bus system with $20 \%$ of load penetration level, $20 \%$ of active power and reactive power load are 56.68 MW and 25.24 MVAR. Table 6 represents the comparison of active power loss, cost of active power loss and the percentage of power and cost loss reduction without DGs and with adding active power DGs, reactive power DGs and active reactive power DGs with constant power factor of bus with respect to its load, using GA and ACO. Figure 7 represents the comparison of average voltage profile of IEEE 30-bus without DGs and with implementing active power DGs, reactive power DGs and active reactive power DGs with constant power factor of bus with respect to its load, using GA and ACO. For this case, two active power DG units are optimally sized and placed using ACO technique; the size and location of each DG are given in Table 2. Show that in fig. 5 and table 7 the bus voltage profile, three active and reactive power DG units are optimally sized and placed using ACO technique, the size and location of each DG and cost of power loss are given table 6. 
OPTIMAL DISTRIBUTED GENERATION PLACEMENT AND SIZING TO REDUCE ACTIVE POWER LOSS USING GA AND ACO ALGORITHM

Table (6): DG placement and sizing and cost of power loss by GA and ACO for IEEE 30-bus system (case2)

\begin{tabular}{|c|c|c|c|c|c|c|c|c|c|c|c|}
\hline \multirow{2}{*}{$\begin{array}{c}\text { DG } \\
\text { MUMBER } \\
\text { NO DG }\end{array}$} & \multirow[t]{2}{*}{ Techniques } & \multirow[t]{2}{*}{$\begin{array}{l}\text { DE } \\
\text { Types }\end{array}$} & \multicolumn{4}{|c|}{ Implemented DG Schadule } & \multirow[t]{2}{*}{$\begin{array}{l}\text { DGs } \\
\text { (MWw) }\end{array}$} & \multirow[t]{2}{*}{$\begin{array}{l}\text { DGs } \\
\text { (MYYAR) }\end{array}$} & \multirow{2}{*}{$\begin{array}{l}\text { Ploss } \\
\text { (miw) } \\
18.744 \\
\end{array}$} & \multirow{2}{*}{$\begin{array}{c}\text { Cost Loss } \\
\text { (IE) } \\
18744\end{array}$} & \multirow{2}{*}{$\begin{array}{c}\text { Costerp } \\
\text { Loss } \\
\text { redurthor } \\
\text { restion } \\
0\end{array}$} \\
\hline & & & & & & & & & & & \\
\hline \multirow{13}{*}{ 2DG } & \multirow{6}{*}{ GA } & $\mathbf{P}$ & $\begin{array}{l}\text { BUS } \\
\text { sis } \\
\text { simen }\end{array}$ & $\begin{array}{c}5 \\
37.31\end{array}$ & $\begin{array}{c}19 \\
12.9\end{array}$ & & 56.71 & 0.0 & 11.054 & 11054 & 41.12 \\
\hline & & \multirow{2}{*}{$\mathbf{a}$} & Bus & 2 & 21 & & \multirow{2}{*}{0.0} & \multirow{2}{*}{25.3} & & \multirow{2}{*}{19123} & \multirow{2}{*}{3.2} \\
\hline & & & sl12e & 12.3 & 13 & & & & 19.128 & & \\
\hline & & \multirow{3}{*}{$\begin{array}{l}\mathbf{P} \\
\mathbf{a}\end{array}$} & Bus & 5 & 21 & & \multirow{3}{*}{56.7} & \multirow{3}{*}{24.6} & \multirow{3}{*}{10.903} & \multirow{3}{*}{10908} & \multirow{3}{*}{ 41.81 } \\
\hline & & & simes & 26.34 & 29.94 & & & & & & \\
\hline & & & Sizer & 5.4 & 19,2 & & & & & & \\
\hline & \multirow{7}{*}{ ACO } & \multirow{2}{*}{$\mathbf{P}$} & Bus & 5 & 30 & & & & & & \\
\hline & & & 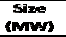 & 50 & 6.69 & & $\mathbf{5 6 . 5 8}$ & 0.0 & 10,989 & 109399 & $\mathbf{4 1 , 4}$ \\
\hline & & $a$ & Bus & 21 & 2 & & 0.0 & 25.24 & 12.13 & 13190 & 3.9 \\
\hline & & & (sions & 12.62 & 12.62 & & & & & & \\
\hline & & $\mathbf{P}$ & Bus & 5 & 23 & & & & & & \\
\hline & & $\mathbf{3}$ & $(\sin 2)$ & 40 & 16.69 & & 56.68 & 16.44 & 10.872 & 10332 & 42 \\
\hline & & a & $\begin{array}{ll}\text { size } \\
\text { muvara }\end{array}$ & 8.1 & $\mathbf{8 . 3 4}$ & & & & & & \\
\hline & & $P$ & Bus & 5 & 19 & 24 & 56.3 & 00 & 10.303 & 10908 & 41.81 \\
\hline & & 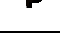 & iman & 41.7 & 8.7 & 6.4 & & & & & \\
\hline & GA & $\mathbf{a}$ & $\begin{array}{l}\text { BUS } \\
\text { Sl=o }\end{array}$ & $\frac{2}{24}$ & $\begin{array}{c}21 \\
10.2\end{array}$ & $\begin{array}{l}19 \\
6.7\end{array}$ & 0.0 & 25.3 & 18.093 & 18093 & $\mathbf{3 . 5}$ \\
\hline & & & Bus & 5 & 21 & 7 & & & & & \\
\hline & & 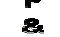 & $\begin{array}{ccc}\text { sines } \\
\text { ensins }\end{array}$ & 36.7 & 14.1 & $\mathbf{5 . 9 3}$ & 55.73 & 19.3 & 10.779 & 10779 & 42.5 \\
\hline & & a & 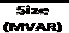 & 7.4 & 9.024 & 2.835 & & & & & \\
\hline 3DG & & & Bus & 5 & 30 & 21 & 5.7 & 0.0 & 10.905 & 10905 & \\
\hline & & P & sisec & 30 & 6.68 & 20 & & & & & 41.52 \\
\hline & & & Bus & 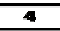 & 23 & 2 & & & & & \\
\hline & Aco & a & Slzen & 3.4 & $\$ .41$ & a.A1 & 0.0 & 25.23 & 13.036 & 120086 & 3.5 \\
\hline & & & BUS & 21 & 30 & 5 & & & & & \\
\hline & & 3 & smasn & 30 & 6.68 & 20 & 56.7 & 24.43 & 10.807 & 10007 & 42.34 \\
\hline & & $\mathbf{a}$ & $\begin{array}{l}\text { sive } \\
\text { anvaran }\end{array}$ & 13.2 & 1.2 & 4.03 & & & & & \\
\hline
\end{tabular}

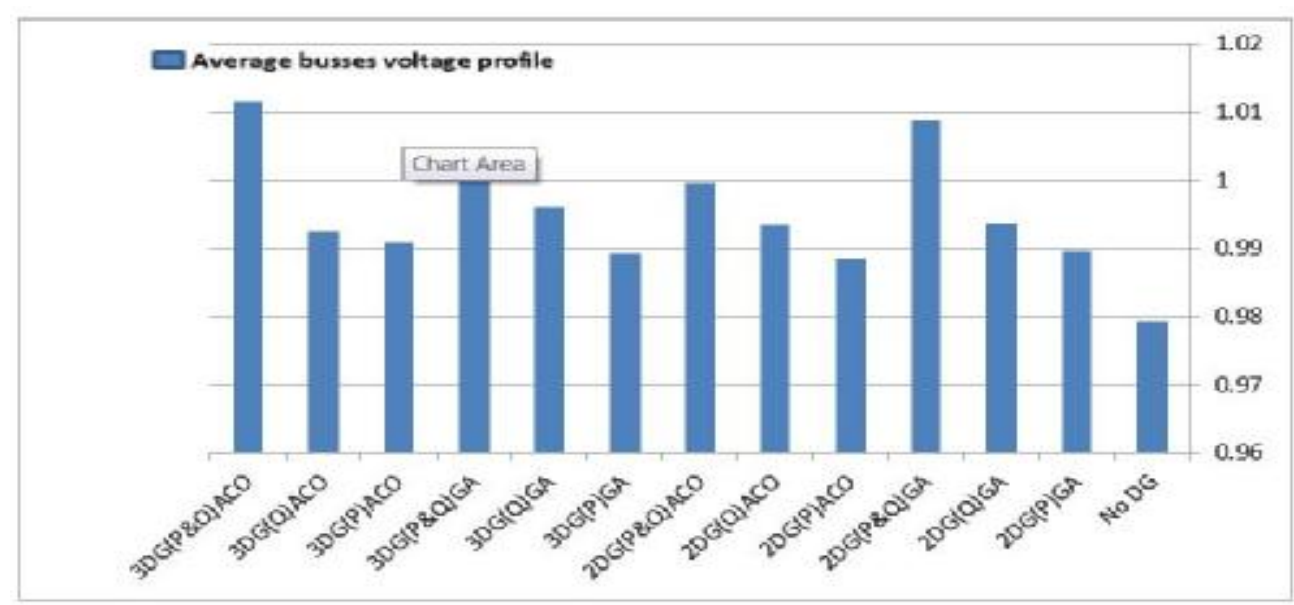

Fig. (7): Average voltages profile of IEEE 30- bus system (case2) 
Table (7): bus voltage profile (case 2)

\begin{tabular}{|c|c|c|c|c|c|c|c|c|c|c|c|c|c|}
\hline \multirow{3}{*}{$\begin{array}{l}\text { Bus } \\
\text { Number }\end{array}$} & \multirow{3}{*}{$\begin{array}{l}\text { Base } \\
\text { Case }\end{array}$} & \multicolumn{6}{|c|}{ Genetic Technique } & \multicolumn{6}{|c|}{ Ant Colony Technique } \\
\hline & & \multicolumn{3}{|c|}{ 2DG Units } & \multicolumn{3}{|c|}{ 3DG Units } & \multicolumn{3}{|c|}{ 2DG Units } & \multicolumn{3}{|c|}{ 3DG Units } \\
\hline & & $\mathbf{P}$ & $\mathbf{Q}$ & P\&Q & $\mathbf{P}$ & $\mathbf{Q}$ & P\&Q & $\mathbf{P}$ & $\mathbf{Q}$ & P\&Q & $\mathbf{P}$ & $\mathbf{a}$ & P\&Q \\
\hline$T$ & 1.06 & 1.06 & 1.06 & 1.06 & 1.06 & 1.06 & 1.06 & 1.06 & 1.06 & 1.06 & 1.06 & 1.06 & 1.06 \\
\hline 2 & 1.01 & 1.02 & 1.02 & 1.02 & 1.02 & 1.02 & 1.02 & 1.02 & 1.02 & 1.02 & 1.02 & 1.02 & 1.02 \\
\hline$\overline{3}$ & 0.99 & 1.00 & 1 & 1 & 1.01 & 1 & 1 & 1.01 & 1 & $\overline{1}$ & 1.01 & $\overline{1}$ & 1 \\
\hline 4 & 0.98 & 0.99 & 0.99 & 0.99 & 1 & 0.99 & 0.99 & 0.99 & 0.99 & 0.99 & 0.99 & 0.99 & 0.99 \\
\hline 5 & 0.97 & 0.99 & 0.99 & 0.98 & 0.99 & 0.99 & 0.98 & 1 & 0.99 & 0.98 & 1 & 0.99 & 0.98 \\
\hline 6 & 0.97 & 0.98 & 0.98 & 0.98 & 0.99 & 0.98 & 0.98 & 0.99 & 0.98 & 0.98 & 0.99 & 0.98 & 0.98 \\
\hline 7 & 0.96 & 0.98 & 0.98 & 0.97 & 0.98 & 0.98 & 0.97 & 0.99 & 0.98 & 0.97 & 0.99 & 0.98 & 0.97 \\
\hline 8 & 0.97 & 0.98 & 0.98 & 0.98 & 0.99 & 0.98 & 0.98 & 0.99 & 0.98 & 0.98 & 0.99 & 0.98 & 0.98 \\
\hline 9 & 0.99 & 1.00 & 1 & 1 & 1.02 & 1 & 1 & 1.01 & 1 & 1 & 1.01 & 1 & 1 \\
\hline 10 & 0.99 & 1.00 & 1 & 1.01 & 1.03 & 0.99 & 1.01 & 1.01 & 1 & 1.01 & 1.01 & 1 & 1 \\
\hline 11 & 1.00 & 1.00 & 1 & 1 & 1.01 & 1 & 1 & 1 & 1 & 1 & 1 & 1 & 1 \\
\hline 12 & 0.99 & 1.00 & 1 & 1.01 & 1.03 & 1 & 1.01 & 1.01 & 1 & 1.01 & 1.01 & 1 & 1.01 \\
\hline 13 & 1.00 & 1.00 & 1 & 1.01 & 1.02 & 1 & 1.01 & 1.01 & 1 & 1.01 & 1.01 & 1 & 1.01 \\
\hline 14 & 0.98 & 0.99 & 0.99 & 1 & 1.01 & 0.99 & 1 & 1 & 0.99 & 1 & 1 & 0.99 & 1 \\
\hline 15 & 0.97 & 0.99 & 0.99 & 1 & 1.02 & 0.98 & 1 & 1 & 0.99 & 1 & 1 & 0.99 & 0.99 \\
\hline 16 & 0.98 & 0.99 & 0.99 & 1 & 1.02 & 0.99 & 1 & 1 & 0.99 & $\overline{1}$ & 1.01 & 0.99 & 1 \\
\hline 17 & 0.98 & 0.99 & 0.99 & 1 & 1.02 & 0.99 & 1 & 1 & 0.99 & 1 & 1 & 0.99 & 1 \\
\hline 18 & 0.97 & 0.99 & 0.99 & 0.99 & 1.01 & 0.97 & 0.99 & 0.99 & 0.98 & 1 & 0.99 & 0.98 & 0.98 \\
\hline 19 & 0.97 & 0.99 & 0.99 & 0.98 & 1 & 0.97 & 0.98 & 0.99 & 0.98 & 1 & 0.99 & 0.98 & 0.98 \\
\hline 20 & 0.97 & 0.99 & 0.99 & 0.99 & 1.01 & 0.98 & 0.99 & 0.99 & 0.98 & 1 & 0.99 & 0.98 & 0.99 \\
\hline 21 & 0.97 & 0.98 & 0.98 & 1 & 1.03 & 0.98 & 1 & 1 & 0.98 & 1 & 1 & 0.99 & 0.99 \\
\hline 22 & 0.98 & 0.99 & 0.99 & 1 & 1.02 & 0.99 & 1 & 1 & 0.99 & 1 & 1 & 0.99 & 0.99 \\
\hline 23 & 0.97 & 0.98 & 0.98 & 1 & 1.02 & 0.98 & 0.99 & 1 & 0.98 & 1 & 1 & 0.99 & 0.99 \\
\hline 24 & 0.97 & 0.98 & 0.98 & 0.99 & 1.01 & 0.98 & 0.99 & 0.99 & 0.98 & 0.99 & 0.99 & 0.98 & 0.98 \\
\hline 25 & 0.97 & 0.98 & 0.98 & 0.89 & 1 & 0.98 & 0.99 & 0.99 & 0.98 & 0.99 & 0.99 & 0.98 & 0.98 \\
\hline 26 & 0.95 & 0.96 & 0.96 & 0.97 & 0.98 & 0.96 & 0.97 & 0.97 & 0.96 & 0.97 & 0.97 & 0.97 & 0.97 \\
\hline 27 & 0.98 & 0.99 & 0.99 & 0.99 & 1.01 & 0.99 & 0.99 & 1 & 0.99 & 0.99 & 1 & 0.99 & 0.99 \\
\hline 28 & 0.97 & 0.98 & 0.98 & 0.98 & 0.99 & 0.98 & 0.98 & 0.99 & 0.98 & 0.98 & 0.99 & 0.98 & 0.98 \\
\hline 29 & 0.96 & 0.97 & 0.97 & 0.97 & 0.99 & 0.98 & 0.97 & 0.98 & 0.97 & 0.97 & 0.98 & 0.98 & 0.97 \\
\hline 30 & 0.95 & 0.96 & 0.96 & 0.97 & 0.98 & 0.98 & 0.97 & 0.97 & 0.96 & 0.97 & 0.97 & 0.98 & 0.97 \\
\hline
\end{tabular}

Case 3: 30\% Penetration Level

The proposed methods are applied to IEEE 30-bus system with $30 \%$ of load penetration level, $30 \%$ of active power and reactive power load are $85.02 \mathrm{MW}$ and 37.86 MVAR. Table 8 represents the comparison of active power loss, cost of active power loss and the percentage of power and cost loss reduction without DGs and with adding active power DGs, reactive power DGs and active reactive power DGs with constant power factor of bus with respect to its load, using GA and ACO. Figure 8 represents the comparison of average voltage profile of IEEE 30-bus without DGs and with implementing active power DGs, reactive power DGs and active reactive power DGs with constant power factor of bus with respect to its load, using GA and ACO. For this case, three active and reactive power DG units are optimally sized and placed using ACO technique; the size and location of each DG are given in Table Ill. Show that in fig.6 the best solution for maximum average voltage profile is; two active and reactive power DG units are optimally sized and placed using ACO technique; the size and location of each DG are given in table 8. 
OPTIMAL DISTRIBUTED GENERATION PLACEMENT AND SIZING TO REDUCE ACTIVE POWER LOSS USING GA AND ACO ALGORITHM

Table (8): DG placement and sizing and cost of power loss by GA and ACO for IEEE 30-bus system (case3)

\begin{tabular}{|c|c|c|c|c|c|c|c|c|c|c|c|}
\hline \multirow{2}{*}{$\begin{array}{c}\text { DG } \\
\text { NUMBER } \\
\text { NO DG }\end{array}$} & \multirow[t]{2}{*}{ Techniques } & \multirow[t]{2}{*}{$\begin{array}{l}\text { DG } \\
\text { Types }\end{array}$} & \multicolumn{4}{|c|}{ Implemented DG Schedule } & \multirow[t]{2}{*}{$\begin{array}{l}\text { DGs } \\
\text { (MW) }\end{array}$} & \multirow[t]{2}{*}{$\begin{array}{c}\text { DGs } \\
\text { (MVAR) }\end{array}$} & \multirow{2}{*}{$\begin{array}{l}\text { PLoss } \\
\text { (MW) } \\
18.744\end{array}$} & \multirow{2}{*}{$\begin{array}{c}\begin{array}{c}\text { Cost Loss } \\
\text { (LE) }\end{array} \\
18744\end{array}$} & \multirow{2}{*}{$\begin{array}{c}\begin{array}{c}\text { Cost8P } \\
\text { Loss } \\
\text { Reduction } \\
(96)\end{array} \\
0\end{array}$} \\
\hline & & & & & & & & & & & \\
\hline \multirow{14}{*}{ 2DG } & \multirow{7}{*}{ GA } & \multirow[b]{2}{*}{$\mathbf{P}$} & BUS & 5 & 21 & & \multirow[b]{2}{*}{85.1} & \multirow[b]{2}{*}{0.0} & \multirow[b]{2}{*}{ 8.392 } & \multirow[b]{2}{*}{8392} & \multirow[b]{2}{*}{55.23} \\
\hline & & & $\begin{array}{c}\text { Size } \\
\text { (MW) }\end{array}$ & 49.25 & 35.8 & & & & & & \\
\hline & & \multirow[b]{2}{*}{$\mathbf{Q}$} & BUS & 3 & 4 & & \multirow[b]{2}{*}{0.0} & \multirow[b]{2}{*}{37.51} & \multirow[b]{2}{*}{17.958} & \multirow[b]{2}{*}{17958} & \multirow[b]{2}{*}{4.2} \\
\hline & & & $\begin{array}{c}\text { Size } \\
\text { (MVAR) }\end{array}$ & $\mathbf{3 . 4}$ & 34.11 & & & & & & \\
\hline & & \multirow{3}{*}{$\begin{array}{l}\mathbf{P} \\
\mathbf{Q} \\
\mathbf{Q}\end{array}$} & BUS & 5 & $\mathbf{8}$ & & \multirow{3}{*}{85.04} & \multirow{3}{*}{41.02} & \multirow{3}{*}{ 8.397 } & \multirow{3}{*}{8397} & \\
\hline & & & $\begin{array}{c}\text { size } \\
\text { (Mm) }\end{array}$ & 55.14 & 29.9 & & & & & & 55.22 \\
\hline & & & $\begin{array}{c}\text { Slze } \\
\text { (Mvar) }\end{array}$ & 11.12 & 29.9 & & & & & & \\
\hline & & & Bus & 5 & 19 & & & & & & \\
\hline & & $\mathbf{P}$ & $\begin{array}{l}\text { Size } \\
\text { (Mw) }\end{array}$ & 70 & 15.02 & & 85.02 & 0.0 & 8.527 & 8527 & 54.51 \\
\hline & & & Bus & 2 & 21 & & & & & & \\
\hline & ACO & $\mathbf{Q}$ & $\begin{array}{c}\text { Size } \\
\text { (Mvar) }\end{array}$ & 18.93 & 18.93 & & 0.0 & 37.9 & 18.109 & 18109 & $\mathbf{3 . 4}$ \\
\hline & & & BUS & 5 & 21 & & & & & & \\
\hline & & 8 & $\begin{array}{c}\text { slze } \\
\text { (Mw) }\end{array}$ & 70 & 15.02 & & 85.02 & 23.733 & 8.326 & 8326 & 55.6 \\
\hline & & $\mathbf{Q}$ & $\begin{array}{c}\text { Size } \\
\text { (MVAR) }\end{array}$ & 14.12 & 9.613 & & & & & & \\
\hline & & & Bus & 5 & 8 & 14 & & & & & \\
\hline & & $\mathbf{P}$ & $\begin{array}{c}\text { Size } \\
\text { (MW) }\end{array}$ & 72.2 & 9.1 & $\mathbf{3 . 4}$ & 84.7 & 0.0 & 8.701 & 8701 & 53.6 \\
\hline & & & Bus & 2 & 15 & 21 & & & & & \\
\hline & $\mathbf{G A}$ & $\mathbf{Q}$ & $\begin{array}{c}\text { Size } \\
\text { (MVAR) }\end{array}$ & 10.1 & 9.7 & 18.13 & 0.0 & $\mathbf{3 7 . 9 3}$ & 18.039 & 18039 & 3.8 \\
\hline & & & BUS & 5 & 15 & 19 & & & & & \\
\hline & & 8 & $\begin{array}{c}\text { Size } \\
\text { (MW) }\end{array}$ & 55.9 & 10.34 & 18.83 & 85.07 & 21.24 & 8.257 & 8257 & 55.95 \\
\hline & & $\mathbf{Q}$ & $\begin{array}{c}\text { Slie } \\
\text { (Mvin) }\end{array}$ & 11.3 & $\mathbf{3 . 2}$ & 6.74 & & & & & \\
\hline 3DG & & & BUS & 5 & 19 & 30 & & & & & \\
\hline & & $\mathbf{P}$ & $\begin{array}{c}\text { Size } \\
\text { (MW) }\end{array}$ & 70 & $\mathbf{8}$ & 7.02 & 85.02 & 0.0 & 8.353 & 8353 & 55.44 \\
\hline & & & BUS & 4 & 22 & 2 & & & & & \\
\hline & $\mathbf{A C O}$ & $\mathbf{Q}$ & $\begin{array}{c}\text { Size } \\
\text { (MVAR) }\end{array}$ & 20 & $\mathbf{8 . 8 5}$ & 7.1 & 0.0 & 35.95 & 17.994 & 17994 & 4 \\
\hline & & & BUS & 23 & 5 & 30 & & & & & \\
\hline & & 8 & $\begin{array}{l}\text { Size } \\
\text { (Mw) }\end{array}$ & 40 & 40 & 5.05 & 85.05 & 28.3 & 8.197 & 8197 & 56.3 \\
\hline & & $\mathbf{Q}$ & $\begin{array}{c}\text { Size } \\
\text { (MVMr) }\end{array}$ & 20 & $\mathbf{8 . 1}$ & 0.2 & & & & & \\
\hline
\end{tabular}

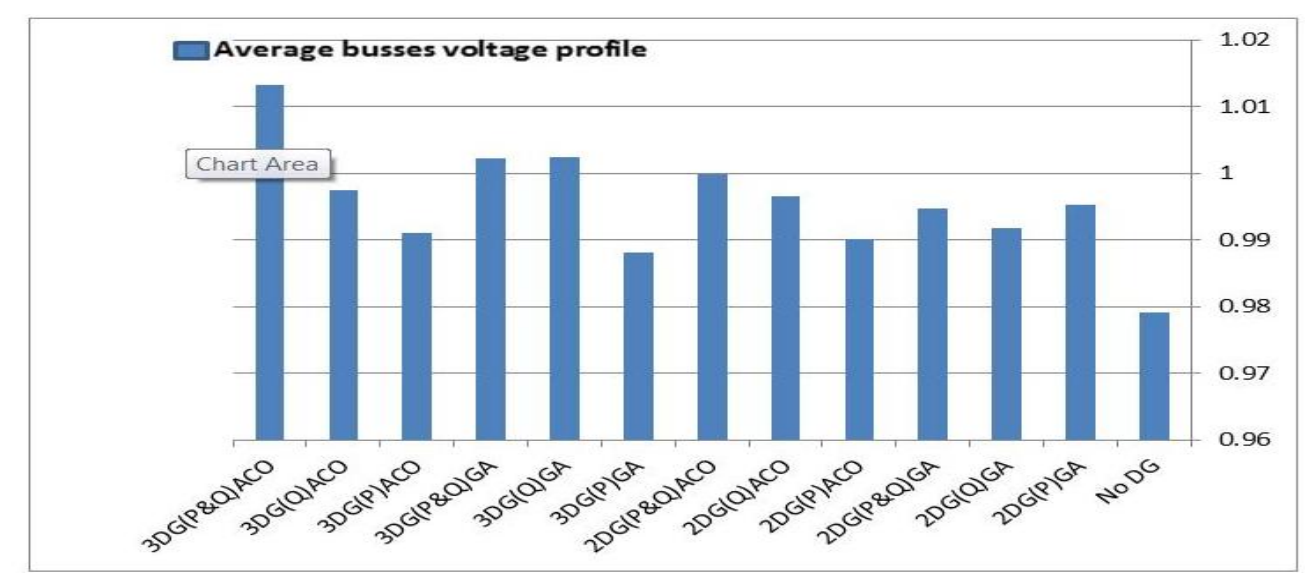

Fig. (8): Average voltages profile of IEEE 30- bus system (case2) 
Table (9): bus voltage profile (case 3 )

\begin{tabular}{|c|c|c|c|c|c|c|c|c|c|c|c|c|c|}
\hline \multirow{3}{*}{$\begin{array}{l}\text { Bus } \\
\text { Number }\end{array}$} & \multirow{3}{*}{$\begin{array}{l}\text { Base } \\
\text { Case }\end{array}$} & \multicolumn{6}{|c|}{ Genetic Technique } & \multicolumn{6}{|c|}{ Ant Colony Technique } \\
\hline & & \multicolumn{3}{|c|}{ 2DG Units } & \multicolumn{3}{|c|}{ 3DG Units } & \multicolumn{3}{|c|}{ 2DG Units } & \multicolumn{3}{|c|}{ 3DG Units } \\
\hline & & $\mathbf{P}$ & $\mathbf{a}$ & P\&Q & $\mathbf{P}$ & $\mathbf{Q}$ & P\&Q & $\mathbf{P}$ & $\mathbf{Q}$ & P\&Q & $\mathbf{P}$ & $\mathbf{Q}$ & P\&Q \\
\hline 1 & 1.06 & 1.06 & 1.06 & 1.06 & 1.06 & 1.06 & 1.06 & 1.06 & 1.06 & 1.06 & 1.06 & 1.06 & 1.06 \\
\hline 2 & 1.01 & 1.02 & 1.02 & 1.02 & 1.02 & 1.02 & 1.02 & 1.02 & 1.02 & 1.02 & 1.02 & 1.02 & 1.02 \\
\hline$\overline{3}$ & 0.99 & 1.01 & 1.01 & 1.01 & 1 & 1 & 1.01 & 1 & 1 & 1.01 & 1 & 1.01 & 1.01 \\
\hline 4 & 0.98 & 0.99 & 1 & 0.99 & 0.99 & 0.99 & 0.99 & 0.99 & 0.99 & 1 & 0.99 & 1 & 1 \\
\hline 5 & 0.97 & 1 & 0.98 & 1 & 1 & 0.98 & 1 & 1 & 0.98 & 1 & 1 & 0.98 & 1 \\
\hline 6 & 0.97 & 0.99 & 0.99 & 0.99 & 0.98 & 0.98 & 0.99 & 0.98 & 0.98 & 0.99 & 0.98 & 0.99 & 1 \\
\hline 7 & 0.96 & 0.99 & 0.98 & 0.99 & 0.98 & 0.97 & 0.99 & 0.98 & 0.97 & 0.99 & 0.98 & 0.98 & 0.99 \\
\hline 8 & 0.97 & 0.99 & 0.99 & 1 & 0.98 & 0.98 & 0.99 & 0.98 & 0.98 & 0.99 & 0.98 & 0.99 & 0.99 \\
\hline 9 & 0.99 & 1 & 1 & 1 & 1 & 1.01 & 1.01 & 1 & 1.01 & 1.01 & 1 & 1.01 & 1.02 \\
\hline 10 & 0.99 & 1 & 1 & 1 & 1 & 1.01 & 1.01 & 0.99 & 1.02 & 1.01 & 1 & 1.01 & 1.03 \\
\hline 11 & 1.00 & 1 & 1 & 1 & 1 & 1 & 1 & 1 & 1 & 1 & 1 & 1 & 1.01 \\
\hline 12 & 0.99 & 1.01 & 1.01 & 1.01 & 1 & 1.01 & 1.01 & 1 & 1.03 & 1.02 & 1 & 1.01 & 1.03 \\
\hline 13 & 1.00 & 1 & $\overline{1}$ & 1 & $T$ & 1.01 & 1.01 & $T$ & 1.02 & 1.01 & 1 & 1.01 & 1.02 \\
\hline 14 & 0.98 & 0.99 & 0.99 & 0.99 & 0.99 & 1 & 1 & 0.99 & 1.02 & 1.01 & 0.99 & 1 & 1.02 \\
\hline 15 & 0.97 & 0.99 & 0.99 & 0.99 & 0.99 & 1 & 1 & 0.99 & 1.02 & 1.01 & 0.99 & 1 & 1.02 \\
\hline 16 & 0.98 & 1 & 1 & 1 & 0.99 & 1.01 & 1.01 & 0.99 & 1.01 & 1.01 & 0.99 & 1 & 1.02 \\
\hline 17 & 0.98 & 1 & 0.99 & 0.99 & 0.99 & $\overline{1}$ & 1 & 0.99 & $\overline{1.01}$ & $\overline{1}$ & 0.99 & 1 & 1.02 \\
\hline 18 & 0.97 & 0.98 & 0.98 & 0.98 & 0.99 & 0.99 & 0.99 & 0.98 & 1 & 1.01 & 0.98 & 0.99 & 1.01 \\
\hline 19 & 0.97 & 0.98 & 0.98 & 0.98 & 0.99 & 0.99 & 0.99 & 0.97 & 1 & 1.02 & 0.98 & 0.99 & 1.01 \\
\hline 20 & 0.97 & 0.99 & 0.98 & 0.98 & 0.99 & 0.99 & 0.99 & 0.98 & 1 & 1.02 & 0.98 & 0.99 & 1.01 \\
\hline 21 & 0.97 & 1 & 0.98 & 0.98 & 0.98 & 1 & 1 & 0.98 & 1.01 & 1 & 0.98 & 0.99 & 1.03 \\
\hline 22 & 0.98 & 1 & 0.99 & 0.99 & 0.99 & 1 & 1 & 0.99 & 1.01 & $\overline{1}$ & 0.99 & 1.01 & 1.02 \\
\hline 23 & 0.97 & 0.99 & 0.98 & 0.98 & 0.98 & 1 & 1 & 0.98 & 1.01 & 1 & 0.98 & 0.99 & 1.03 \\
\hline 24 & 0.97 & 0.99 & 0.98 & 0.98 & 0.98 & 0.99 & 0.99 & 0.98 & 1 & 0.99 & 0.98 & 0.99 & 1.02 \\
\hline 25 & 0.97 & 0.99 & 0.98 & 0.99 & 0.98 & 0.99 & 0.99 & 0.98 & 0.99 & 0.99 & 0.98 & 0.99 & 1.01 \\
\hline 26 & 0.95 & 0.97 & 0.97 & 0.97 & 0.96 & 0.97 & 0.97 & 0.96 & 0.98 & 0.97 & 0.96 & 0.97 & 0.99 \\
\hline 27 & 0.98 & 1 & 1 & 1 & 0.99 & 1 & 1 & 0.99 & 1 & 1 & 0.99 & 1 & 1.01 \\
\hline 28 & 0.97 & 0.99 & 0.99 & 0.99 & 0.98 & 0.98 & 0.99 & 0.98 & 0.98 & 0.99 & 0.98 & 0.99 & 1 \\
\hline 29 & 0.96 & 0.98 & 0.98 & 0.98 & 0.97 & 0.98 & 0.98 & 0.97 & 0.98 & 0.98 & 0.98 & 0.98 & 1 \\
\hline 30 & 0.95 & 0.97 & 0.97 & 0.97 & 0.96 & 0.97 & 0.97 & 0.96 & 0.97 & 0.97 & 0.98 & 0.97 & 1 \\
\hline
\end{tabular}

\section{V.CONCLUSION}

In perspective of consistently expanding load demand in the power sector, DG is playing an extremely indispensable role to enhance the system performance by diminishing the real power loss and enhancing the voltage profile. Optimal size and position of DG are very important in the utilization of DG for loss minimization and voltage profile enhancement in electric power system. Inappropriate position of DG in the system process will prompt the negative impact on system task. This paper presents population based heuristic methods i.e. GA and ACO algorithms are used to put the optimal sizing of DG at suitable position. To approve the proposed technique, IEEE30-bus system is tested and the results obtained are compared. The results are tabulated and the average voltage profile enhancement is indicated graphically and tabulated. Reduction in active power losses and enhancement in voltage profile can be noticed. The results demonstrated that the implementation of DG in ACO is exceedingly viable in reduction total losses of real power and voltage profile enhancement compared with GA.

\section{REFERENCES}

[1] Ismael, S., Abdel Aleem, S., Abdelaziz, A., \& Zobaa, A. (2018). Practical Considerations for Optimal Conductor Reinforcement and Hosting Capacity Enhancement in Radial Distribution Systems. IEEE Access, 6, 27268-27277. 
[2] Alhamali, A., Farrag, M., Bevan, G., \& Hepburn, D. (2017). Determination of optimal site and capacity of DG systems in distribution network based on genetic algorithm. $201752 \mathrm{Nd}$ International Universities Power Engineering Conference (UPEC).

[3] Alkaabi, S., Zeineldin, H., \& Khadkikar, V. (2018). Adaptive planning approach for customer DG installations in smart distribution networks. IET Renewable Power Generation, 12(1), 81-89.

[4] Saad, M., El-Ghany, H., \& Azmy, A. (2017). Optimal DG deployment to improve voltage stability margin considering load variation. 2017 Nineteenth International Middle East Power Systems Conference (MEPCON).

[5] Uniyal, A., \& Kumar, A. (2016). Comparison of optimal DG placement using CSA, GSA, PSO and GA for minimum real power loss in radial distribution system. 2016 IEEE 6Th International Conference On Power Systems (ICPS).

[6] Chen, X., Wu, W., Zhang, B., \& Lin, C. (2017). Data-Driven DG Capacity Assessment Method for Active Distribution Networks. IEEE Transactions On Power Systems, 32(5), 3946-3957.

[7] Kanth, D., Reddy, N., \& Reddy, R. (2017). Optimal placement \& sizing of DG's using backtracking search algorithm in IEEE 33-bus distribution system. 2017 International Conference On Computing Methodologies And Communication (ICCMC).

[8] Kumari, R., Kumar, G., Nagaraju, S., \& Jain, M. (2017). Optimal sizing of distributed generation using particle swarm optimization. 2017 International Conference On Intelligent Computing, Instrumentation And Control Technologies (ICICICT).

[9] Oda, E., \& Abdelsalam, A. (2017). Optimal DGs allocation in distribution networks using modified flower pollination algorithm. 2017 Nineteenth International Middle East Power Systems Conference (MEPCON).

[10] Zou, B., Wang, J., \& Wen, F. (2017). Optimal investment strategies for distributed generation in distribution networks with real option analysis. IET Generation, Transmission \& Distribution, 11(3), 804-813.

[11] Mitra, J., Vallem, M., \& Singh, C. (2016). Optimal Deployment of Distributed Generation Using a Reliability Criterion. IEEE Transactions On Industry Applications, 52(3), 1989-1997.

[12] Prasanna, K., Jain, A., \& Kumar, R. (2017). Optimal distributed generation placement using hybrid technique. 2017 IEEE PES Asia-Pacific Power And Energy Engineering Conference (APPEEC).

[13] Sarfaraz, S., Bansal, A., \& Singh, S. (2016). Optimal allocation and sizing of distributed generation for power loss reduction. International Conference \& Workshop On Electronics \& Telecommunication Engineering (ICWET 2016).

[14] Dixit, M., Kundu, P., \& Jariwala, H. (2016). Optimal placement and sizing of DG in Distribution system using Artificial Bee Colony Algorithm. 2016 IEEE 6Th International Conference On Power Systems (ICPS).

[15] Abbasi, F., \& Hosseini, S. (2016). Optimal DG allocation and sizing in presence of storage systems considering network configuration effects in distribution systems. IET Generation, Transmission \& Distribution, 10(3), 617-624.

[16] Ameri, A., Nichita, C., Riouch, T., \& El-Bachtiri, R. (2015). Genetic algorithm for optimal sizing and location of multiple distributed generations in electrical network. 2015 Modern Electric Power Systems (MEPS).

[17] Kumar, D., Tianyi, H., Srinivasan, D., Reindl, T., \& Shenoy, U. (2015). Optimal distributed generation allocation using evolutionary algorithms in meshed network. 2015 IEEE Innovative Smart Grid Technologies - Asia (ISGT ASIA).

[18] Gopiya Naik, S., Khatod, D., \& Sharma, M. (2015). Analytical approach for optimal siting and sizing of distributed generation in radial distribution networks. IET Generation, Transmission \& Distribution, 9(3), 209-220.

[19] Elsaiah, S., Benidris, M., \& Mitra, J. (2014). Analytical approach for placement and sizing of distributed generation on distribution systems. IET Generation, Transmission \& Distribution, 8(6), 1039-1049.

[20] Falaghi, H., \& Haghifam, M. (2007). ACO Based Algorithm for Distributed Generation Sources Allocation and Sizing in Distribution Systems. 2007 IEEE Lausanne Power Tech. 
[21] Ugranli, F., \& Karatepe, E. (2012). Genetic algorithm for weight assignment in optimum planning of multiple distributed generations to minimize energy losses. 2012 International Symposium On Innovations In Intelligent Systems And Applications. 